\title{
INCLUSION COMPLEX OF THE ANTIVIRAL DRUG ACYCLOVIR WITH CYCLODEXTRIN IN AQUEOUS SOLUTION AND IN SOLID PHASE
}

Carlos von Plessing Rossel*

Facultad de Farmacia - Departamento de Farmacia - Casilla, 237 - Universidad de Concepción - Concepción - Chile Jacqueline Sepúlveda Carreño

Facultad de Ciencias Biológicas - Departamento de Farmacología - Casilla, 160-C - Universidad de Concepción - Concepción - Chile Mario Rodríguez-Baeza

Facultad de Ciencias Químicas - Departamento de Polímeros - Casilla, 3-C - Universidad de Concepción - Concepción - Chile Joel Bernabé Alderete

Facultad de Ciencias Químicas - Departamento de Orgánica - Casilla, 3-C - Universidad de Concepción - Concepción - Chile

Recebido em 29/10/99; aceito em 18/4/00

\begin{abstract}
Complexation between acyclovir (ACV), an antiviral drug used for the treatment of herpes simplex virus infection, and $\beta$-cyclodextrin $(\beta-C D)$ was studied in solution and in solid states. Complexation in solution was evaluated using solubility studies and nuclear magnetic resonance spectroscopy $\left({ }^{1}\right.$ H-NMR). In the solid state, X-ray diffraction, differential scanning calorimetry (DSC), thermal gravimetric analysis (TGA) and dissolution studies were used. Solubility studies suggested the existence of a 1:1 complex between ACV and $\beta$-CD. ${ }^{1} \mathrm{H}$-NMR spectroscopy studies showed that the complex formed occurs with a stoichiometry ratio of 1:1. Powder X-ray diffraction indicated that ACV exists in a semicrystalline state in the complexed form with $\beta$-CD. DSC studies showed the existence of a complex of ACV with $\beta$-CD. The TGA studies confirmed the DSC results of the complex. Solubility of ACV in solid complexes was studied by the dissolution method and it was found to be much more soluble than the uncomplexed drug.
\end{abstract}

Keywords: cyclodextrin; acyclovir; inclusion complex.

\section{INTRODUCTION}

Acyclovir (9-((2-hydroxyethoxy)-methyl)-guanine, is an acyclic analogue of the natural nuleoside 2'-deoxyguanine with antiviral activity "in vitro" against herpes simplex viruses (HSV), varicella zoster virus (VZV), Epstein-Barr virus (EBV), cytomegalovirus (CMV) and human herpes virus 6 (HHV-6) ${ }^{1}$.

The fundamental pharmacokinetic properties of acyclovir are well established ${ }^{2,3}$. The intravenous administration of acyclovir is described as a two-compartment open model and the absorption of orally administered acyclovir is slow, variable and incomplete with an oral bioavailability of $15-30 \%{ }^{4,5}$. The effects of dosage size on the extent of oral absorption are not well understood. Some reports suggest that absorption from the gastrointestinal tract may be a saturable, dose-dependent process ${ }^{6,7}$. In contrast, another study reported a relative constancy in the urinary recovery of unchanged drug and in the bioavailability calculated from urinary excretion data, concluding that the net absorption of acyclovir is nearly proportional to the dose ${ }^{8}$.

The limited absorption of ACV can be improved with a sustained release formulation ${ }^{9}$, by using a prodrug of $\mathrm{ACV}$ (Descyclovir) $^{10}$ (Fig.1), or with ACV modified by acetylation and coupling obtaining a drug-polymer conjugate ${ }^{11}$. Another possible way to overcome this problem is by modifying the solubility of the drug by using cyclodextrins and their derivatives. Cyclodextrins are able to form inclusion complexes with a wide variety of drugs and the interaction can affect many of the observed physicochemical properties, such as aqueous solubility and stability ${ }^{12-14}$. Formation of inclusion

*e-mail: cvonples@udec.cl complexes with $\beta$-CD has been used extensively to improve the solubility of poorly soluble drugs ${ }^{2-4,12-15}$ and their dissolution rate ${ }^{5}$. Loftsson et al. ${ }^{16}$ were able to double the ACV solubility by incorporating it in a $50 \% \mathrm{w} / \mathrm{w}$ aqueous solution of 2-hydroxypropyl- $\beta$-cyclodextrin.<smiles>Nc1ncc2ncn(CCOCCO)c2n1</smiles>

(a)<smiles>Nc1nc2c(ncn2COCCO)c(=O)[nH]1</smiles>

(b)
Figure 1. Structural formulae of Descyclovir (A) and Acyclovir (B).

The purpose of this investigation is to study the complexation of ACV with CDs and their effect on ACV solubility by using techniques obtained from studying other type of complexes (e.g. X-ray diffraction, solubility studies, dissolution rate, differential scanning calorimetry, thermal gravimetry and nuclear magnetic resonance spectroscopy).

\section{MATERIALS AND METHODS}

\section{Materials}

Acyclovir was donated by Laboratorio Chile, Laboratorio Saval (Santiago, Chile) and Laboratorio Pasteur (Concepción, Chile). $\beta$-CD was kindly supplied by Roquette (Lestrem, 
France). All other materials were of analytical grade. Deionized and double-distilled water was used throughout the study.

\section{Methods}

\section{Solubility studies}

Solubility studies were carried out according to the Higuchi and Connors method ${ }^{17}$. $\beta$-CD solutions of different concentrations $\left(13.2-2,81 * 10^{-3} \mathrm{M}\right)$ were added to a supersaturated solution of ACV and shaken at room temperature $\left(22 \pm 1{ }^{\circ} \mathrm{C}\right)$ for 36 hours. After reaching equilibrium, the solutions were filtered. The concentration of ACV in the filtrate was determined spectrophotometrically at $290 \mathrm{~nm}$ with reference to a suitably constructed standard curve.

\section{Preparation of the solid complex}

A solid complex of $\beta-\mathrm{CD}$ with ACV was prepared at a $1: 1$ molar ratio. The physical mixture (Ph.M) was prepared by simply mixing the powders with a spatula. A freeze-dried complex (C) was prepared by drying an aqueous solution containing ACV/ $\beta$ $\mathrm{CD}$ in a 1:1 molar ratio in a Virtis" Freeze-Dryer.

\section{Differential Scanning Calorimetry (DSC) and Thermal Gravimetric Analysis (TG)}

Thermal analyses were performed on solid and freeze-dried samples obtained directly from the preparation medium. DSC and TGA data were obtained using a Polymer Laboratories (STA-625) Thermal analyzer. Samples $(2-6 \mathrm{mg})$ were heated in sealed aluminum pans under nitrogen flow $\left(50 \mathrm{~cm}^{3} \mathrm{~min}^{-1}\right)$ at a heating rate of $10^{\circ} \mathrm{C} \mathrm{min}-1$, from 50 to $400^{\circ} \mathrm{C}$.

\section{X-ray diffraction studies}

Powder X-ray diffraction patterns were recorded using a Siemens Kristalloflex D-501 with the following conditions: Nifiltered $\mathrm{CuK}$ radiation, voltage $36 \mathrm{kV}$, current $26 \mathrm{~mA}$, at a scanning rate of $2 \% \mathrm{~min}$.

\section{Dissolution studies}

Accurately weighed amounts of the powdered ACV, Ph.M. and $\mathrm{C}$, each containing $100 \mathrm{mg} \mathrm{ACV}$, were used to carry out the studies in a Dissolution Test 6 device (Hanson Research Corp. Northridge, California, USA) using the USP XXIII paddle method. The dissolution medium consisted of $900 \mathrm{~mL}$ of distilled water at $37^{\circ} \mathrm{C} \pm 0.5^{\circ} \mathrm{C}$ and a stirring speed $=50 \mathrm{rpm}$. The progress of the dissolution was followed by circulating the dissolution medium through the cell of the spectrophotometer for continuous recording over $30 \mathrm{~min}$, at $290 \mathrm{~nm}$.

\section{Nuclear magnetic resonance studies}

The inclusion complexes of ACV- $\beta-\mathrm{CD}$ were characterized in deutered water by ${ }^{1} \mathrm{H}-\mathrm{NMR}$. The spectra were obtained in a Brucker AC250 (250.13 MHz for $1 \mathrm{H})$ spectrophotometer. The chemical displacements are reported as relative to the solvent residual signal, HDO $(\delta=4.800 \mathrm{ppm})$. The conditions employed were: $16 \mathrm{~K}$ data points, weep width $5 \mathrm{khz}$, pulse width $4 \mu$ s and numbers of scan 600 .

\section{RESULTS AND DISCUSSION}

The solubility of ACV in water is very low, $1.3 \mathrm{mg} \cdot \mathrm{mL}^{-1}$ at $25^{\circ} \mathrm{C}$, as previously reported ${ }^{18}$. Figure 2 shows the solubility curve obtained for ACV with $\beta$-CD. The resulting linear curve can be classified, in general, as type $\mathrm{A}_{\mathrm{L}}{ }^{17}$, indicating that complexes with a 1:1 stoichiometry will be present in the solution.

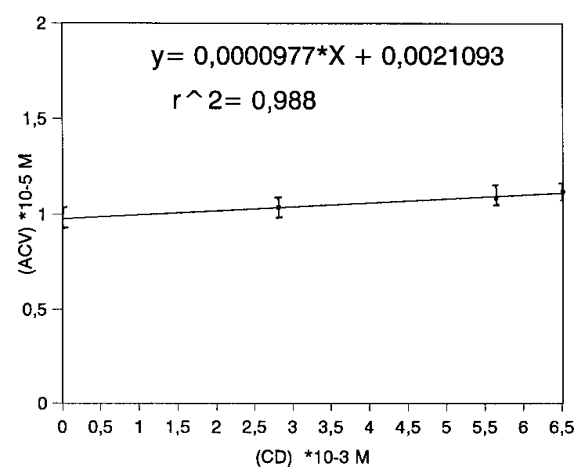

Figure 2. Higuchi phase solubility diagram of $\beta C D$ and acyclovir.

UV absorbance of ACV is not affected in the presence of $\mathrm{CD}$. The apparent solubility constant $\mathrm{K}_{1: 1}$ was calculated from the curve according to Eq. 1 and was found to be $22 \mathrm{M}^{-1}$

$\mathrm{K}_{1: 1}=$ slope $/$ So (1-slope)

where So is the solubility of ACV in the absence of $\beta-C D$.

DSC measurements (Fig. 3) show an endothermic peak at the ACV melting point $\left(249^{\circ} \mathrm{C}\right)$. However, with the physical mixture, this peak was absent in the diagram of the inclusion compound. Because of its molecularly dispersed distribution and the protection that the complexation affords, the peak was not detected due to its displacement to the decomposition temperature of the $\beta-C D$.
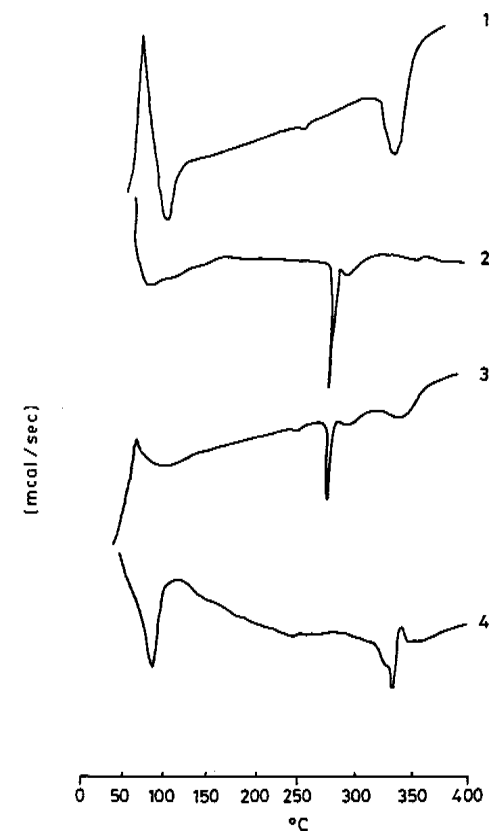

Figure 3. DSC thermograms of (1) $\beta C D$, (2) acyclovir, (3) physical mixture, (4) inclusion complex $(1: 1)$.

TG measurements are shown in Figure 4, where CD, ACV, Ph.M. and C (1:1) are represented. Therefore, it was determined that when the physical mixture is prepared some complex is also formed. This is confirmed by the fact that the weight loss due to degradation, when a proportional quantity of the physical mixture is weighed with respect to the pure drug, is not equivalent to that of the drug alone. In the complex thermogram no variation 
is observed in the degradation area of the drug indicating that it has acquired a state different to that of the drug and that of the physical mixture, that is, an inclusion complex has been formed.

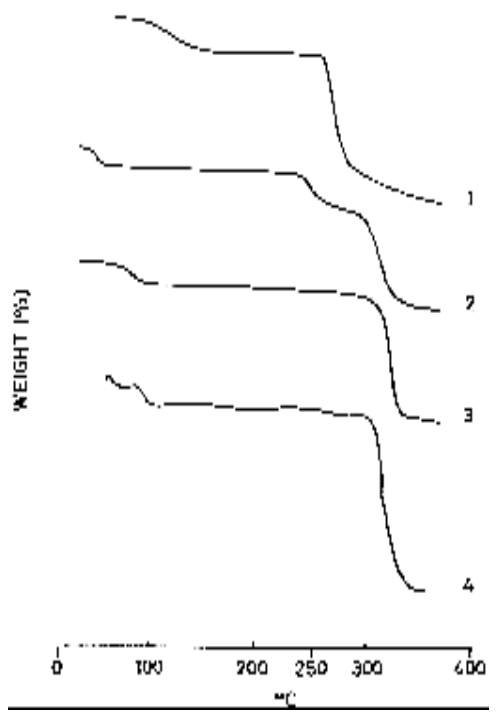

Figure 4. TG thermograms of (1) acyclovir, (2) physical mixture, (3) $\beta C D$, (4) inclusion complex (1:1).

The X-ray diffraction pattern of the inclusion compound differed considerably from that of the drug or the $\beta-C D$ alone (Fig. 5). In contrast the diffraction pattern of the physical mixture showed that in addition to the presence of the pure drug, the complex formation is also obtained, a fact shown by appearance of new peaks. The diffractogram of the complex indicated a new solid phase, the inclusion compound; whose diffractogram shows a different crystalline state which is similar to that of other complexes described in literature ${ }^{19}$.

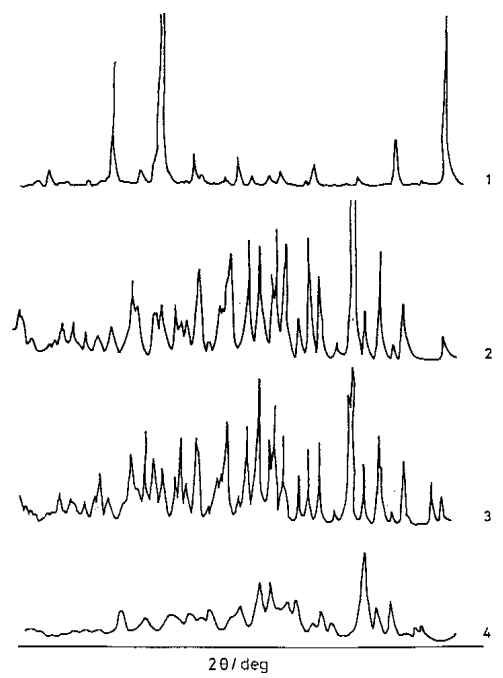

Figure 5. X-Ray diffractograms of (1) acyclovir, (2) $\beta C D$, (3) physical mixture, (4) inclusion complex (1:1).

The dissolution rate (Fig. 6) of the drug in the inclusion compound was evidently higher than that of the drug alone. This can be attributed to the increase in solubility. Another factor that could have been involved in the improved solubility is the decrease in crystallinity of the inclusion complex which was confirmed by the X-ray diffraction results.

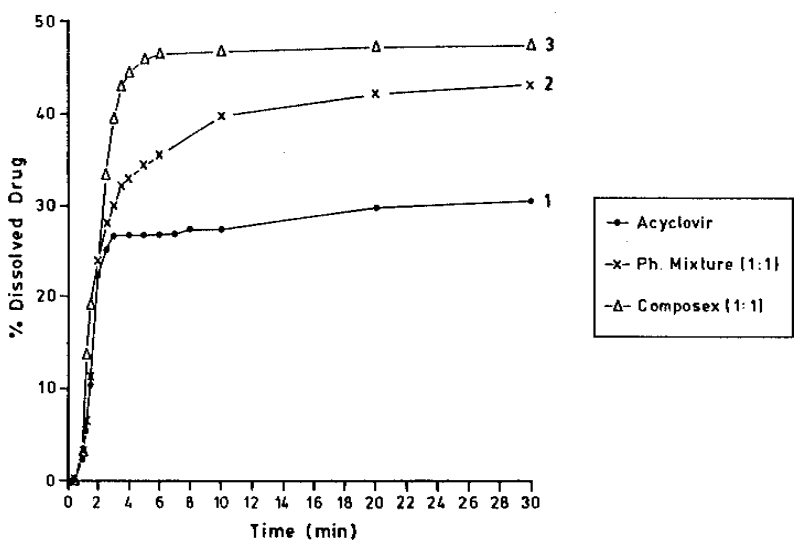

Figure 6. Dissolution studies of (1) acyclovir, (2) physical mixture, (3) inclusion complex (1:1).

With the physical mixture, a small increase in dissolution rate was obtained which can be explained due to the formation of a minimum quantity of the complex. After 3 minutes, the quantity of ACV dissolved from the $\beta$-CD complex was 1.3 times greater than that of the physical mixture. During the same period, the quantity of dissolved ACV alone was 2.0 times lower than that dissolved from the complex.

Although solubility studies indicated the existence of complexation between ACV and $\beta-C D$ in solution, a deeper insight into the complexation mechanism was obtained from ${ }^{1} \mathrm{H}-\mathrm{NMR} .{ }^{1} \mathrm{H}-$ NMR spectra for acyclovir in DMSO- $\mathrm{d}_{6}$ and $\mathrm{D}_{2} \mathrm{O}$ for the ACV/ $\beta$ $\mathrm{CD}$ complex in $\mathrm{D}_{2} \mathrm{O}$ are shown in Table 1 . Due to the interchange with deuterium, in deutered water only signals corresponding to protons $\mathrm{H} 8, \mathrm{H} 10$ and $\mathrm{H} 11 / \mathrm{H} 12$ of the $\mathrm{ACV}$ were detected. In the case of the complex, a small displacement of the signals corresponding to $\mathrm{H} 8(0.012 \mathrm{ppm})$ and $\mathrm{H} 10(0.014 \mathrm{ppm})$ of the ACV was observed. The slight displacement at low field of these signals indicates a low efficiency in the acyclovir complexation. In spite of this fact it was possible to determine the stoichiometry of the complex using the continuous variation method ${ }^{29}$. For this study equimolar solutions of $\mathrm{ACV}$ and $\beta-\mathrm{CD}$ were prepared and mixed at a standard volume $(1 \mathrm{~mL})$ in such proportions that the sum of the concentrations of $\mathrm{ACV}$ and $\beta-\mathrm{CD}$ remained constant and equal to $10 \mathrm{mM}$. Afterwards, the change in the chemical displacement of signal $\mathrm{H} 8$ of $\mathrm{ACV}$ as a function of $\mathbf{r}$, where $\mathbf{r}$ is the ratio of the initial concentrations defined by $\mathbf{R}=(\mathbf{A C V}) /$ $((\mathbf{A C V})+(\beta-\mathbf{C D}))$, was determined. The results of these experiments are shown in Figure 7. As can be seen in this figure, the curve achieves a maximum at $\mathbf{R}=\mathbf{0 . 5}$, indicating the formation of a 1:1 stoichiometric complex. However, due to the low complexation efficiency, it is very difficult to compare the magnitude of the signals displacement of $1 \mathrm{H}$ of $\beta-\mathrm{CD}$ making it impossible to obtain information about the complex structure.

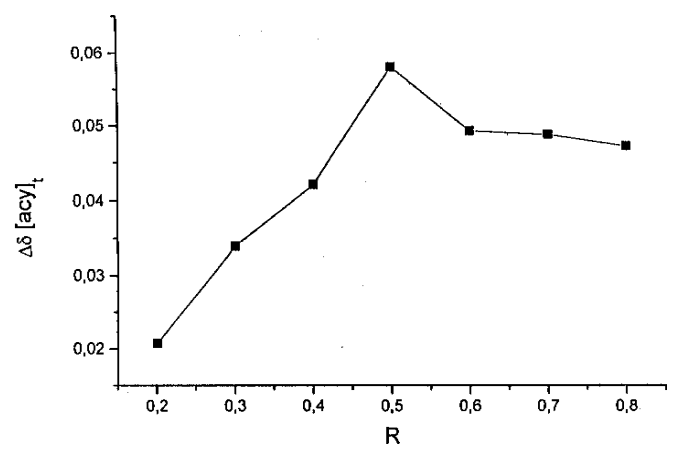

Figure 7. Job plot derived from ${ }^{1} H-N M R$ study of the interaction of acyclovir with $\beta C D$. 
Table 1. Chemical displacements of ACV and ACV- $\beta C D$ complex.

\begin{tabular}{ccccccc}
\hline & $\mathrm{N} 1-\mathrm{H}$ & $\mathrm{H} 8$ & $\mathrm{NH}_{2}$ & $\mathrm{H} 10$ & $\mathrm{OH}$ & $\mathrm{H} 11 / \mathrm{H} 12$ \\
\hline Acyclovir $^{\mathbf{a}}$ & 10.921 & 7.893 & 6.674 & 5.465 & 4.803 & 3.575 \\
Acyclovir $^{\mathbf{b}}$ & & 7.912 & & 5.965 & & 3.653 \\
Complex $^{\mathbf{c}}$ & & 7.924 & & 5.509 & & \\
\hline
\end{tabular}

${ }^{\text {a } \text { In DMSO-d }}$. Solvent signal used as reference $(2.600 \mathrm{ppm})$

b In $\mathrm{D}_{2} \mathrm{O}$. In this case due to the interchange with deuterium the signals of interchangeable ${ }^{1} \mathrm{H}$ are not detected.

${ }^{\text {c }}$ In $\mathrm{D}_{2} \mathrm{O}$. Concentrations; ACV $5 \mathrm{mM}$ and $\beta$ CD $5 \mathrm{mM}$. Signals $\mathrm{H} 11 / \mathrm{H} 12$ are overlapped with the signals of $\mathrm{C} 2$ protons of the $\beta C D$.

\section{CONCLUSION}

Acyclovir forms an inclusion compound (1:1) with $\beta-\mathrm{CD}$ in the solid and the solution state. This was confirmed by DSC, TGA, X-ray diffraction and NMR spectroscopy. Complexation by inclusion increases ACV solubility and dissolution. Dissolution increase is due to the decreased activity of the complexed ACV in solution and the low crystallinity of the formed complex as confirmed by the X-ray diffraction pattern. The solubility of the physical mixture, when compared to that of the complex was improved to a lesser degree.

\section{ACKNOWLEDGEMENT}

This research was supported by the Dirección de Investigación, Universidad de Concepción (Grant $\mathbf{N}^{0}$ 96.074.022 - 1.1D).

\section{REFERENCES}

1. Wagstaff Antona, J.; Faulds, D.; Goa Karen, L.; Drugs 1994, 47, 153.

2. Duchene, D.; Vaultion, C.; Glomot, F.; Drug Dev. Ind. Pharm. 1986, 12, 2193.

3. Erden, N.; Celebi, N.; Int. J. Pharm. 1988, 48, 83.

4. Hamada, Y.; Nambu, N.; Nagai, T.; Chem. Pharm. Bull. 1975, 23, 1205 .

5. Corrigan, O. I.; Stanly, C. T.; J. Pharm. Pharmacol. 1982, 34,621 .
6. Bridgen, D.; Fowle, A.; Rosling, A.; Developments in antiviral therapy (Eds. Collier LH \& Oxford I.) Academic Press, 1980; p. 53-62.

7. Vergin, H.; Kikuta, C.; Mascher, H.; Metz, R.; Arzneimittel-Forschung/Drug Research 1995, 45, 508.

8. de Miranda, P.; Krasny, H. C.; Page, D. A.; Elion, C. B.; Am. J. Med. 1982, 73, 31.

9. Lewis, L. D.; Fowle, A. S. E.; Bittner, S. B.; Bye A. and Isaacs, P. E. T.; Br. J. Clin. Pharmacol. 1986, 21, 459.

10. Richards, D. M.; Carmine, A. A.; Brodgen, R. N.; Heel, R. C.; Speight, T. M.; Drugs 1983, 26, 378.

11. Fiamona, G.; Puglisi, G.; Cavallaro, G.; Spadaro A.; and Pitanesi, G.; J. Controlled Release 1995, 32, 261.

12. Saenger, W.; Angew. Chem. Int. Ed. Engl. 1980, 19, 344.

13. Szejtli, J.; Controlled Drug Bioavailability (Ed. W. F. Smolen; L. A. Ball), Vol. 3 Wiley, N.Y. 1985; p. 365.

14. Szejtli, J.; Medicinal Applications of Cyclodextrins, in Medicinal Research Reviews, 1994; Vol. 14, N ${ }^{\mathrm{a}} 3$, p. 364

15. Frömming, K. H.; Prc. Ist Int. Symp. Cyclodextrins (Ed. J. Szejtli) Reidel, Drodrecht, 1982; p. 367

16. Loftsson, Th.; Bodor, N.; Acta Pharm. Nord. 1989, 1, 185.

17. Higuchi, T.; Connors, K. A.; Adv. Anal. Chem. Instrum. 1965, 4, 117.

18. Drug Information 95, American Hospital Formulary Service, Ed. Gerald, K. McEvoy, USA, 1995; p.2388.

19. Fridrich, R.; Mehnert, W.; Frömming, K. H.; Minutes of the $5^{\text {th }}$ Int. Symp. on Cyclodextrins, (Ed. D. Duchene), Editions de Santé Publishers, Paris, 1990; p. 299.

20. Loukas, Y. L.; J. Pharm. Pharmacol. 1997, 49, 944. 